\title{
Occupation during life and risk of dementia in French elderly community residents
}

\author{
C Helmer, L Letenneur, I Rouch, S Richard-Harston, P Barberger-Gateau, C Fabrigoule, \\ J M Orgogozo, J F Dartigues
}

\begin{abstract}
Objective-To determine whether principal occupation during life is a risk factor for incident Alzheimer's disease, vascular dementia, or dementia with parkinsonism.

Methods-This study was carried out from the PAQUID (Personnes Agées QUID) cohort, an epidemiological study on normal and pathological aging after 65 years in the south west of France. At baseline, 2950 non-demented people living at home were identified and re-examined 1 , $3,5,8$, and 10 years later with identical standardised neurological and neuropsychological measures. Cox proportional hazards models with delayed entry were used, taking age as the time scale and adjusting for sex, education, tobacco, and wine consumption to estimate the risk ratio (RR) of incident dementia,
\end{abstract} Alzheimer's disease, vascular dementia, and dementia with parkinsonism associated with occupational category.

Results-Of the 2950 subjects, 393 became demented, of whom 251 had Alzheimer's disease, 112 had vascular dementia, and 27 had dementia with parkinsonism. The risk of Alzheimer's disease was not related to a given occupation. However the risk of dementia with parkinsonism seemed to be increased in farmers in comparison with professionals and managerials, particularly among women (RR 7.47; 95\%CI, 1.80-31.07).

Conclusion-The data suggest that occupation does not change the risk of Alzheimer's disease, which seems to be more influenced by cognitive abilities in childhood and adolescence than by occupation in adult life. However, being a farmer may increase the risk of dementia with parkinsonism among women; occupation could act by the way of differences in health behaviour or in exposure to environmental factors.

(F Neurol Neurosurg Psychiatry 2001;71:303-309)

Keywords: non-Alzheimer's dementia; risk factor; occupational category; parkinsonism

If convincing evidence has been presented for a link between educational level and the risk of cognitive decline ${ }^{1-3}$ despite some noteworthy negative findings, ${ }^{4}$ the question of the relation between occupation and dementia is both more complex and more controversial.
The complexity of this relation is due to the fact that occupational category is at the same time an indicator of exposure to chemicals or other environmental factors, the reflection of psychosocial characteristics of people, particularly cognitive stimulations throughout life, a socioeconomic indicator of medical care and attitude to health, and a surrogate marker of premorbid intelligence. After adjustment for educational level, some authors have found a significant increase in the risk of dementia in manual versus non-manual workers ${ }^{5-8}$ whereas others have not found any significant association. ${ }^{9-12}$ Differences in study group size, in design, in case findings of dementia, and in definitions of occupational categories could explain these discrepancies. As for other socioeconomic indicators, case-control studies and cross sectional prevalence studies on occupation and dementia may be particularly biased by selection ${ }^{12}$ and survival. ${ }^{13}$ As postulated by Evans et $a l,{ }^{11}$ large population based cohort studies with active search for incident cases of dementia and change in cognitive function, although expensive and time consuming, are probably the most reasonable approaches to study such factors.

In previous papers based on the cross sectional analysis of the baseline screening of the PAQUID study, a prospective population based cohort of elderly people in south western France,${ }^{14}{ }^{15}$ we have shown that principal occupation during life is strongly associated with global cognitive performances measured by the mini mental state examination (MMSE) ${ }^{16}$ and with memory performances, independently of educational level. Whatever the psychometric test analysed, farmers have the lowest cognitive performances whereas professionals and managerial staff (teachers, professionals, and executives) have the highest. The 10 year follow up of this cohort now offers the opportunity to analyse the effect of occupation on the risk of incident dementia. Moreover, the cumulative number of incident cases (393) allows a sufficiently powerful statistical analysis to study the risk of aetiological subtypes of dementia.

\section{Methods}

The PAQUID cohort is based on a representative sample of 5554 people living at home in south west France (Gironde and Dordogne). Among them, a total of 3777 people living at home $(68 \%)$ agreed to participate in the study. This cohort is the subject of an epidemiological study on normal and pathological aging in the over 65 population, focused on non-genetic risk factors in dementia. Subjects were seen at 
home by a psychologist specially trained for home interviews. The baseline variables recorded included sociodemographic factors, social support and network, living conditions and habits, subjective and objective health measures, a comprehensive functional assessment, depressive symptomatology, current symptoms and diseases, and neurosensory impairments. A more complete description of the baseline data collected in the PAQUID study has been published previously. ${ }^{14}{ }^{15}$ An ethics review committee has approved the PAQUID study.

Occupation during active life was recorded during the baseline interview. If the person was cognitively impaired, help of a proxy was required. Only the occupation undertaken during the longest part of active life was taken into account for this paper. The occupations were classified into seven categories according to the Institut National des Statistiques et Etudes Economiques (INSEE) classification: ${ }^{17}$ housewives and inactives, farmers (farm workers and farm managers), domestic service employees, blue collar workers (skilled and unskilled blue collar workers, drivers), other employees (white collar workers, business employees, nurses, policemen, and soldiers), craftsmen and shopkeepers, professionals and managerials (teachers, professionals, managers, and executives). The last category was considered as the reference category as previously used by Stern et al. ${ }^{6}$ We have regrouped the categories housewifes and inactives, because both are heterogeneous. In addition, there were only 20 "inactive" subjects in our cohort. At the baseline screening, a random sample of refusals (200 subjects) was interviewed by phone and non-responders did not differ from responders in age, sex, and educational level. The distribution of the study sample for the different occupational categories was almost the same as the contacted sample. ${ }^{15}$ Farmers, professionals/managerials, and craftsmen were slightly more numerous in the study sample, whereas other occupations were slightly less numerous.

To analyse the relation between occupation and risk of dementia we adjusted for the main risk factors which could bias the association between occupation and dementia: adjustment variables were sex, education considered in two levels (at least primary school level validated by a diploma versus no diploma). Wine consumption/day was classified into four categories: mild drinker (about 1/4 1), moderate drinker (about $1 / 21$ ), or heavy drinker (more than $1 / 2$ 1) compared with the reference category of no consumption. Smoking habits were classified into three categories: never smokers, former smokers, and current smokers. The income was classified into three categories: high (payment of income taxes), medium (no payment of income taxes but no drawing of the French pension for poor elderly people, the Fond National de Solidarité, FNS), and low (for those drawing of the FNS pension). Three vascular factors were also considered: treated diabetes (yes versus no), hypertension (reported usual systolic blood pressure $>140 \mathrm{~mm} \mathrm{Hg}$ or reported usual diastolic blood pressure $>90 \mathrm{~mm} \mathrm{Hg}$ ), and history of stroke at baseline (yes or no).

Intellectual functioning was examined through a series of psychometric tests that have been shown to be among the most sensitive for assessing cognitive decline in elderly people. After the psychometric evaluation, the psychologists systematically completed a standardised questionnaire designed to obtain the A (memory impairment), B (impairment of at least one other cognitive function), and C (interference with social or professional life) criteria for DSM-III R dementia. ${ }^{18}$ In a second stage, subjects who met these first three DSMIII R criteria for dementia were seen by a senior neurologist who confirmed and completed the DSM-III R criteria for dementia, and filled in the NINCDS-ADRDA criteria ${ }^{19}$ and the Hachinski score for vascular dementia ${ }^{20}$ to document the diagnosis of dementia and its aetiology: probable or possible Alzheimer's disease, vascular dementia or Alzheimer's disease with cerebrovascular disease, and other types of dementia. An informant was consulted by the neurologist when available. All ancillary information, including medical charts and reports of brain imaging if available, was included in the evaluation. Comparable procedures of screening of dementia are usually used in other cohort studies. $^{21}$

\section{FOLLOW UP}

Subjects were re-evaluated by the same procedure as for the baseline screening $1,3,5,8$, and 10 years after the initial visit in Gironde and 3, 5 and 8 years in Dordogne. Subjects were re-evaluated even if they were institutionalised. The case finding and the aetiological categorisation of incident cases of dementia followed the same procedure at each follow up assessment as for the baseline screening, but another criterion was added for the qualification of subjects in the second stage-that is, the neurological examination. Subjects were selected for this stage if they met the A,B, and C DSM III-R criteria for dementia or if they had lost three points or more on the MMSE score.

\section{CLASSIFICATION OF INCIDENT CASES OF} DEMENTIA

For this study, all available information useful for the aetiological diagnosis of incident cases of dementia was reviewed by a senior neurologist (SRH). This specialist applied the following clinical criteria for each aetiological category: NINCDS-ADRDA criteria for Alzheimer's disease, NINDS-AIREN criteria for vascular dementia, ${ }^{22}$ recommendations of the NINDS-AIREN international workshop for Alzheimer's disease with cerebrovascular disease, ${ }^{22}$ Lund and Manchester criteria for frontotemporal dementia, ${ }^{23}$ McKeith et al criteria for Lewy body disease, ${ }^{24}$ NINDS-SPSP criteria for progressive supranuclear palsy, ${ }^{25}$ and Consensus Committee of the American Autonomic society and the American Academy of Neurology criteria for multiple system atrophy. ${ }^{26}$ 
Table 1 Follow up status of the PAQUID cohort according to the occupational category. PAQUID 1988-1997

\begin{tabular}{lcccc}
\hline Occupational category & $\begin{array}{l}\text { Followed up } \\
(n(\%))\end{array}$ & $\begin{array}{l}\text { Refused } \\
(n(\%))\end{array}$ & $\begin{array}{l}\text { Died } \\
(n(\%))\end{array}$ & $\begin{array}{l}\text { Total } \\
(n(\%))\end{array}$ \\
\hline Housewives/inactives & $282(75.0)$ & $46(12.2)$ & $48(12.8)$ & $376(100)$ \\
Farmers & $451(80.4)$ & $38(6.8)$ & $72(12.8)$ & $561(100)$ \\
Domestic service employees & $253(80.3)$ & $33(10.5)$ & $29(9.2)$ & $315(100)$ \\
Blue collar workers & $498(78.1)$ & $65(10.2)$ & $75(11.7)$ & $638(100)$ \\
Other employees & $785(82.8)$ & $76(8.0)$ & $87(9.2)$ & $948(100)$ \\
Craftsmen/shopkeepers & $400(80.2)$ & $32(6.4)$ & $67(13.4)$ & $499(100)$ \\
Professionals/managerials & $281(83.1)$ & $22(6.5)$ & $35(10.4)$ & $338(100)$ \\
Total & $2950(80.3)$ & $312(8.5)$ & $413(11.2)$ & $3675(100)$ \\
\hline
\end{tabular}

STATISTICAL ANALYSIS

Age specific incidence was estimated using the person-years (py) method. ${ }^{27}$ The risk ratio (RR) and 95\% confidence interval (95\% CI) of dementia, Alzheimer's disease, vascular dementia, and dementia with parkinsonism were estimated using a Cox proportional hazards model with delayed entry, in which the time scale was the subject's age. ${ }^{28}$ To evaluate the independent role of occupation for the risk of dementia, we adjusted for possible confounders. For each aetiology of dementia, four models were performed: model 1 , with adjustment for sex and interaction between sex and age, as we have previously shown a nonproportionality of incidence rates with age $^{3}$; model 2 where we added education into the previous model; model 3 with in addition adjustment for risk factors wine and tobacco consumption; and model 4 where we added level of income and vascular factors. Global effect of occupation was tested using the log likelihood ratio statistics.

\section{Results}

Among the 3777 subjects who constituted the PAQUID cohort, 102 were demented at baseline and were excluded from the study sample. The 3675 initially non-demented subjects included 2133 (58\%) women and 1822 subjects $(49.6 \%)$ older than 74 . The main occupation during active life was distributed as follows: 376 housewives and inactives $(10.2 \%)$, 561 farmers $(15.3 \%), 315$ domestic service employees $(8.6 \%), 638$ blue collar workers $(17.4 \%), 948$ other employees (25.8\%), 499 craftsmen and shopkeepers (13.6\%), and 338 professionals and managerials $(9.2 \%)$. Repartition differed according to sex. In women, $17.5 \%$ were housewives and inactives, $14.8 \%$ were farmers, $13.7 \%$ were domestic service employees, $14.1 \%$ were blue collar workers, $23.5 \%$ were other employees, $11.3 \%$ were craftsmen and shopkeepers, and $5.1 \%$ were professionals and managerials. In men, these proportions were respectively $0.1 \%, 15.8 \%$, $1.4 \%, 21.9 \%, 29.0 \%, 16.7 \%$, and $14.9 \%$.

Of the 3675 non-demented subjects, 725 $(19.7 \%)$ did not participate in any follow up visit because they died $(n=413 ; 11.2 \%)$ or were either lost to follow up or refused the follow up screenings $(n=312 ; 8.5 \%)$. At least one complete follow up evaluation was performed on 2950 subjects $(80.3 \%)$. In comparison with professionals and managerials, the reduction in size of the cohort with time was more pronounced in all the other occupational categories, but the difference was only important for housewives and inactives (25\% not followed up versus $16.9 \%$ ) (table 1 ). The mean duration of follow up of the cohort was 6.4 years.

Three hundred and ninety three subjects developed an incident dementia, of whom 251 were classified as incident cases of Alzheimer's disease, 112 as vascular dementia or Alzheimer's disease with cerebrovascular disease, and 30 as other types of dementia (16 Lewy body disease, eight dementias complicating an idiopathic Parkinson's disease, two progressive supranuclear palsies, one multiple system atrophy, three frontotemporal dementias). Because of very few frontotemporal dementias, which cannot be collapsed with another subtype of dementia, these three cases have been excluded from the analyses. The 27 other cases of other types of dementia were taken into account as a simple category in the analyses, called dementia with parkinsonism. Incidence of dementia according to occupational category and aetiology of dementia are presented in table 2. Whatever the aetiological subtype of dementia, the lowest incidence was found for professionals and managerials. Farmers had the higher incidence of dementia all causes, of vascular dementia, and of dementia with parkinsonism. As we found no case of dementia with parkinsonism in professionals and managerials, we have regrouped them with other employees, for whom incidence of dementia was the lowest after professionals and managerials.

Using a Cox model with delayed entry with adjustment for sex and interaction age by sex, the risk of dementia was significantly greater in farmers $(\mathrm{RR}=1.67 ; 95 \% \mathrm{CI} 1.23-2.27)$ and in blue collar workers $(\mathrm{RR}=1.51$; 95\% CI 1.10 2.07) than in the reference category of professionals, managerials, and other employees, whereas it did not differ significantly for other

Table 2 Incidence rates of dementia, Alzheimer's disease (AD), vascular dementia (VD), and dementia with parkinsonism (DP) according to the occupational category

\begin{tabular}{|c|c|c|c|c|c|c|c|c|c|}
\hline \multirow[b]{2}{*}{ Occupational category } & \multirow[b]{2}{*}{$p y^{\star}$} & \multicolumn{2}{|c|}{ Dementia } & \multicolumn{2}{|l|}{$A D$} & \multicolumn{2}{|l|}{$V D$} & \multicolumn{2}{|c|}{$D P$} \\
\hline & & $n$ & $\% p y^{*}$ & $n$ & $\% p y^{\star}$ & $n$ & $\% p y^{*}$ & $n$ & $\% p y^{*}$ \\
\hline Housewives/inactives & 1803 & 44 & 2.44 & 29 & 1.61 & 11 & 0.61 & 4 & 0.22 \\
\hline Farmers & 2741 & 78 & 2.85 & 40 & 1.46 & 28 & 1.02 & 10 & 0.36 \\
\hline Domestic service employees & 1612 & 41 & 2.54 & 25 & 1.55 & 15 & 0.93 & 1 & 0.06 \\
\hline Blue collar workers & 2967 & 69 & 2.33 & 48 & 1.62 & 16 & 0.54 & 3 & 0.10 \\
\hline Other employees & 5183 & 90 & 1.74 & 63 & 1.22 & 22 & 0.42 & 5 & 0.096 \\
\hline Craftsmen/shopkeepers & 2666 & 50 & 1.88 & 31 & 1.16 & 14 & 0.53 & 4 & 0.15 \\
\hline Professionals/managerials & 1960 & 21 & 1.07 & 15 & 0.77 & 6 & 0.31 & 0 & 0.00 \\
\hline Total & 18932 & 393 & 2.08 & 251 & 1.33 & 112 & 0.59 & 27 & 0.14 \\
\hline
\end{tabular}

${ }^{\star}$ py $=$ Person-years. 
Table 3 Risk of dementia according to the occupational category. Cox model with delayed entry. PAQUID 1988-97

\begin{tabular}{|c|c|c|c|c|c|c|c|c|}
\hline \multirow[b]{2}{*}{ Dementia } & \multicolumn{2}{|l|}{ Model $1+$} & \multicolumn{2}{|c|}{ Model $2+$} & \multicolumn{2}{|c|}{ Model 3t } & \multicolumn{2}{|c|}{ Model $4 \dagger$} \\
\hline & $R R$ & $95 \% C I$ & $R R$ & $95 \% C I$ & $R R$ & $95 \% C I$ & $R R$ & $95 \% C I$ \\
\hline \multicolumn{9}{|l|}{ Occupational category: } \\
\hline Professionals/managerials and other employees & 1 & - & 1 & - & 1 & - & 1 & - \\
\hline Housewives/inactives & 1.17 & $0.80-1.72$ & 1.05 & $0.71-1.56$ & 1.04 & $0.70-1.53$ & 0.99 & $0.67-1.47$ \\
\hline Farmers & $1.67^{\star \star}$ & $1.23-2.27$ & 1.23 & $0.88-1.72$ & 1.23 & $0.88-1.72$ & 1.08 & $0.75-1.56$ \\
\hline Domestic service employees & 1.16 & $0.77-1.74$ & 0.86 & $0.56-1.32$ & 0.86 & $0.56-1.32$ & 0.79 & $0.51-1.23$ \\
\hline Blue collar workers & $1.51^{\star}$ & $1.10-2.07$ & 1.19 & $0.85-1.66$ & 1.19 & $0.85-1.67$ & 1.15 & $0.82-1.61$ \\
\hline Craftsmen/shopkeepers & 1.07 & $0.75-1.53$ & 1.00 & $0.70-1.42$ & 1.00 & $0.70-1.42$ & 0.93 & $0.64-1.34$ \\
\hline Log likelihood ratio statistics $\ddagger$ & \multicolumn{2}{|l|}{$\mathrm{p}=0.016$} & \multicolumn{2}{|c|}{$\mathrm{p}=0.538$} & \multicolumn{2}{|c|}{$\mathrm{p}=0.541$} & \multicolumn{2}{|c|}{$\mathrm{p}=0.602$} \\
\hline
\end{tabular}

†Model $1=$ sex, interaction age-sex; model $2=$ sex, interaction age-sex, education; model $3=$ sex, interaction age-sex, education, tobacco and wine consumption; model $4=$ sex, interaction age-sex, education, tobacco and wine consumption, income, vascular factors.

$\ddagger$ Testing the global effect of occupation.

${ }^{\star} \mathrm{p}<0.05,{ }^{\star \star} \mathrm{p}<0.01$.

occupational categories (table 3, model 1). Presence of occupational categories significantly improved the fit of the model, as the log likelihood ratio statistic (LRS) was 13.9 $(p<0.016)$. These significant relations disappeared after adjustment for education (table 3, model 2), and occupational categories no longer improved the model compared with one adjusted only for sex, interaction age by sex, and education (LRS $\mathrm{p}=0.538$ ). For models 3 and 4 , the results were unchanged. According to the aetiology of dementia, occupational categories did not modify the risk of Alzheimer's disease. Although the global effect of occupational categories was not significant, there was a tendency to an increased risk of vascular dementia in farmers (RR 1.90; 95\% CI 1.053.43), even after adjustment for education. This risk among farmers remained virtually unchanged when the occupational categories were adjusted for sex, interaction age by sex, education, and even for wine consumption and smoking habits (RR 1.88; 95\% CI 1.04 to 3.41). To explain this relation between occupation and risk of vascular dementia we adjusted for two other possible confounding factors: presence of at least one vascular factor (diabetes, hypertension, or history of stroke), and level of income. The presence of at least one vascular factor was significantly associated with the risk of vascular dementia $(R R=2.09$; 95\% C 1.38-3.18) and explained the relation between occupation and vascular dementia as the risk ratio among farmers decreased and was no longer significant ( $R R=1.56$; 95\% CI 0.82 2.97). The risk of dementia with parkinsonism was also increased among farmers $(R R=4.65$; 95\%CI 1.58-13.65) (table 4, model 1), with a nearly significant global effect of occupation
(LRS; $p=0.074)$. This increased risk of dementia with parkinsonism was not modified when adjusted for sex, interaction age by sex, education, and for wine consumption and smoking habits (RR 4.43; 95\%CI 1.39-14.14), and even after adjustment for vascular factors and level of income (RR 4.64; 95\% CI 1.30-16.61, table 4, models 3 and 4).

Because of the differences according to occupation between sex, the previous results were verified for each sex separately. Risk of Alzheimer's disease seemed to be associated with occupation differently among sex: being a craftsman and shopkeeper was associated with a protective risk among women (RR 0.44; 95\% CI 0.23-0.87) whereas the risk was increased among men (RR 2.05; 95\%CI 1.02-4.11), even after adjustment for confounders. However, the global effect of occupational categories was not significant either for women or for men. For vascular dementia, the results were similar in both sexes; the increased risk found among farmers before introduction of adjustment factors disappeared after introduction of confounders. The increased risk of dementia with parkinsonism found among farmers in the total sample was seen particularly in women, with a significant global effect of occupational categories $(p=0.004$, table 5). After adjustment for education and wine consumption, RR was 7.47 (95\% CI 1.80-31.07). For men there was no significant relation between farmers and dementia with parkinsonism; the apparent effect of domestic service employees was caused by only one case of dementia with parkinsonism (table 6). Moreover, the global effect of occupational categories did not reach significance among men.

Table 4 Risk of dementia with parkinsonism according to the occupational category. Cox model with delayed entry. PAQUID 1988-97

\begin{tabular}{|c|c|c|c|c|c|c|c|c|}
\hline \multirow[b]{2}{*}{ Dementia with parkinsonism } & \multicolumn{2}{|l|}{ Model $1 \dagger$} & \multicolumn{2}{|l|}{ Model $2 \dagger$} & \multicolumn{2}{|l|}{ Model $3 t$} & \multicolumn{2}{|c|}{ Model $4 t$} \\
\hline & $R R$ & $95 \% C I$ & $R R$ & $95 \% C I$ & $R R$ & $95 \% C I$ & $R R$ & $95 \% C I$ \\
\hline \multicolumn{9}{|l|}{ Occupational category: } \\
\hline Professionals/managerials and other employees & 1 & - & 1 & - & 1 & - & 1 & - \\
\hline Housewives/inactives & 2.10 & $0.47-9.35$ & 2.14 & $0.48-9.55$ & 1.99 & $0.45-8.90$ & 2.06 & $0.45-9.32$ \\
\hline Farmers & $4.65^{\star \star}$ & $1.58-13.65$ & $4.95^{\star \star}$ & $1.55-15.81$ & $4.43^{\star}$ & $1.39-14.14$ & $4.64^{\star}$ & $1.30-16.61$ \\
\hline Domestic service employees & 0.78 & $0.09-6.95$ & 0.83 & $0.09-7.64$ & 0.77 & $0.08-7.03$ & 0.80 & $0.09-7.55$ \\
\hline Blue collar workers & 1.37 & $0.33-5.74$ & 1.43 & $0.33-6.21$ & 1.41 & $0.33-6.08$ & 1.47 & $0.33-6.44$ \\
\hline Craftsmen/shopkeepers & 1.84 & $0.49-6.88$ & 1.87 & $0.50-6.98$ & 1.77 & $0.47-6.63$ & 1.85 & $0.48-7.20$ \\
\hline Log likelihood ratio statistics $\ddagger$ & $\mathrm{p}=0.074$ & & $\mathrm{p}=0.084$ & & $\mathrm{p}=0.124$ & & $\mathrm{p}=0.174$ & \\
\hline
\end{tabular}

†Model $1=$ sex, interaction age-sex; model $2=$ sex, interaction age-sex, education; model $3=$ sex, interaction age-sex, education, tobacco and wine consumption; model $4=$ sex, interaction age-sex, education, tobacco and wine consumption, income, vascular factors.

$\ddagger$ Testing the global effect of occupation.

${ }^{\star} \mathrm{p}<0.05,{ }^{\star \star} \mathrm{p}<0.01$. 
Table 5 Risk of dementia with parkinsonism among women according to the occupational category. Cox model with delayed entry. PAQUID 1988-97

\begin{tabular}{|c|c|c|c|c|c|c|c|c|}
\hline \multirow[b]{2}{*}{ Dementia with parkinsonism } & \multicolumn{2}{|l|}{ Model $1+$} & \multicolumn{2}{|c|}{ Model $2+$} & \multicolumn{2}{|c|}{ Model $3 t$} & \multicolumn{2}{|l|}{ Model $4 \uparrow$} \\
\hline & $R R$ & $95 \% C I$ & $R R$ & $95 \% C I$ & $R R$ & $95 \% C I$ & $R R$ & $95 \% C I$ \\
\hline \multicolumn{9}{|l|}{ Occupational category: } \\
\hline Professionals/managerials and other employees & 1 & - & 1 & - & 1 & - & 1 & - \\
\hline Housewives/inactives & 1.84 & $0.37-9.16$ & 2.05 & $0.41-10.29$ & 2.03 & $0.40-10.20$ & 2.23 & $0.44-11.26$ \\
\hline Farmers & $5.42^{\star}$ & $1.42-20.55$ & $7.63^{\star \star}$ & $1.84-31.62$ & $7.47^{\star \star}$ & $1.80-31.07$ & $10.25^{\star \star}$ & $2.10-49.95$ \\
\hline Regrouped class $\ddagger$ & 0.50 & $0.08-3.01$ & 0.63 & $0.10-3.84$ & 0.62 & $0.10-3.78$ & 0.75 & $0.12-4.79$ \\
\hline Log likelihood ratio statistics $\ddagger$ & \multicolumn{2}{|l|}{$\mathrm{p}=0.004$} & \multicolumn{2}{|l|}{$\mathrm{p}=0.002$} & \multicolumn{2}{|c|}{$\mathrm{p}=0.002$} & \multicolumn{2}{|l|}{$\mathrm{p}=0.002$} \\
\hline
\end{tabular}

†Model 1=without adjustment variables; model 2=education; model 3=education, wine consumption; model 4=education, wine consumption, income, vascular factors.

$\ddagger$ Blue-collar workers and domestic service employees have been regrouped with craftsmen/shopkeepers because there was not any cases of dementia with parkinsonism in these two categories.

†Testing the global effect of occupation.

${ }^{\star} \mathrm{p}<0.05,{ }^{\star \star} \mathrm{p}<0.01$.

Table 6 Risk of dementia with parkinsonism among men according to the occupational category. Cox model with delayed entry. PAQUID 1988-97

\begin{tabular}{|c|c|c|c|c|c|c|c|c|}
\hline \multirow[b]{2}{*}{ Dementia with parkinsonism } & \multicolumn{2}{|l|}{ Model $1 \dagger$} & \multicolumn{2}{|l|}{ Model $2+$} & \multicolumn{2}{|l|}{ Model 3t } & \multicolumn{2}{|l|}{ Model $4 t$} \\
\hline & $R R$ & $95 \% C I$ & $R R$ & $95 \% C I$ & $R R$ & $95 \% C I$ & $R R$ & $95 \% C I$ \\
\hline \multicolumn{9}{|l|}{ Occupational category: } \\
\hline Professionals/managerials and other employees & 1 & - & 1 & - & 1 & - & 1 & - \\
\hline Farmers & 2.37 & $0.33-16.91$ & 1.54 & $0.19-12.62$ & 1.36 & $0.17-10.98$ & 0.71 & $0.07-7.41$ \\
\hline Domestic service employees & $21.18^{\star}$ & $1.85-243.2$ & $18.23^{\star}$ & $1.54-215.5$ & $13.94^{\star}$ & $1.17-166.1$ & $26.23^{\star}$ & $1.95-352.4$ \\
\hline Blue collar workers & 3.24 & $0.54-19.42$ & 2.49 & $0.39-15.96$ & 2.46 & $0.39-15.65$ & 1.64 & $0.23-11.56$ \\
\hline Craftsmen/shopkeepers & 2.16 & $0.30-15.41$ & 1.92 & $0.27-13.90$ & 1.85 & $0.26-13.42$ & 1.12 & $0.14-9.07$ \\
\hline Log likelihood ratio statisticsł & $\mathrm{p}=0.319$ & & $\mathrm{p}=0.418$ & & $\mathrm{p}=0.474$ & & $\mathrm{p}=0.314$ & \\
\hline
\end{tabular}

†Model 1=without adjustment variables; model 2=education; model 3=education, tobacco and wine consumption; model 4=education, tobacco and wine consumption, income, vascular factors.

$\ddagger$ Testing the global effect of occupation.

${ }^{\star} \mathrm{p}<0.05,{ }^{\star \star} \mathrm{p} p<0.01$.

\section{Discussion}

OCCUPATION AND ALZHEIMER'S DISEASE

This 10 year follow up of 2950 initially non-demented French elderly people with prospective screening of incident dementia shows that occupational category has no major impact on the risk of Alzheimer's disease. These findings contrast with the strong relation found at the baseline screening phase of the cohort, between cognitive performance and principal lifetime occupation. ${ }^{14}$ This confirms previous analyses conducted on population based cohort studies with active search for incident cases of dementia in Canberra ${ }^{12}$ and east Boston, ${ }^{11}$ but is in conflict with the New York City study ${ }^{6}$ which is very close to the present study from a methodological point of view. Stern et $a l^{6}$ found a significant effect of low occupational attainment on the risk of Alzheimer's disease independently of education. A lack of power cannot explain our negative results as the number of people followed up and the number of incident cases of Alzheimer's disease seen in the present study (2950 and 251 respectively) are far greater than in the New York City study (593 and 97 respectively). It could be argued that our study lacks validity in the aetiological diagnosis of dementia, as the diagnosis was essentially based on the clinical evaluation made at home by a senior neurologist, and brain imaging was available in only $29 \%$ of the 393 incident cases ( $v 78 \%$ in the New York city study). However, the good accuracy of the NINCDS-ADRDA clinical criteria for the diagnosis of Alzheimer's disease is well accepted by the scientific community. ${ }^{29}$ An indirect confirmation is given by the total absence of increased risk of Alzheimer's disease associated with the presence of vascular factors (RR 0.98). Moreover, the neurologist was not aware of the research hypothesis tested in this paper, and the clinical classification was thus conducted independently of occupational category. Differences in the occupational categories considered in the analysis could be another explanation. However, if the same classification as the New York City study (high occupation=professional and managerials; low occupation=other occupations) is taken, the relation remained nonsignificant (RR 1.18; 95\%CI 0.66-2.11). The differences could be explained by the fact that adjustment for the diploma validating primary school education which we used in our study might be more precise than the adjustment for the number of years of schooling used by Stern et al. ${ }^{6}$ We have recently reported that the evaluation of level of education by this diploma was the best classification for predicting Alzheimer's disease in France. ${ }^{3}$ It was essentially based on linguistic and conceptual ability assessed by reading, writing, and spelling tests and mathematical problem solving. The Nun study $^{30}$ has also shown the major impact of these abilities on the risk of Alzheimer's disease. Indeed, even when we used the definition of low education used by Stern et $a l^{6}$ ( 8 years of schooling) we did not find any significant relation between occupation and Alzheimer's disease (RR 1.11; 95\% CI 0.592.07). Thus it seems that the risk of Alzheimer's disease late in life has more to do with cognitive abilities in childhood and adolescence than with lifestyle and environment in adult life.

OCCUPATION AND NON-ALZHEIMER'S DISEASE DEMENTIA

The risk of vascular dementia tended to be increased among farmers, but this increased 
risk was explained by a higher proportion of vascular risk factors among farmers than among professionals, managerials, and other employees. On the contrary, we found an increased risk of dementia with parkinsonism among farmers, even after adjustment for confounders, but significant only for women.

Several methodological issues may have influenced these results. The reduction in the cohort size with time could interfere with our findings. However, our proportion of subjects who did not participate in any follow up is close to that in other cohort studies. ${ }^{1121}$ Farmers refused to continue to participate or died before follow up slightly more than professionals, managerials, and other employees. However, the proportion of subjects successfully contacted remained high in each occupational category $(>75 \%)$ and the differences in follow up of the subjects might essentially lead to an underestimation of the risk ratios.

As in all cohort studies, selective survival before entry into the cohort has to be considered. However, according to occupation, in France, as in other developed countries, survival is longer among professionals and managerials than among farmers; thus, if a selective survival bias exists, it would tend to underestimate the risk of dementia among farmers compared with professionals, managerials, and other employees.

On the other hand, farmers may simply perform worse on the psychometric tests used to screen for dementia whereas those with other occupations might perform better. However, in such a cohort study, the diagnosis at follow up necessarily implies decline from baseline performance and the final diagnosis was made by a senior neurologist. These procedures should minimise the detection bias. Moreover, reduction in the cohort size over time and detection biases, if present, were as great in Alzheimer's disease as in other types of dementia whereas significant relations were found only in nonAlzheimer's disease dementia.

Cognitive stimulation and premorbid intelligence have been proposed to explain the relation between education and incident dementia or Alzheimer's disease. A similar part played by occupation is unlikely as an association was found only for dementia with parkinsonism. Other explanations can be discussed and should be explored, such as differences in health behaviour according to occupation and differences in physical activity or nutrition. The toxic effect of chronic exposure to chemicals related to occupation and particularly pesticides in farmers already implicated in Parkinson's disease, ${ }^{31}$ could also be an explanation for this specific association.

The relation between farmers and dementia with parkinsonism in women has been found in a small sample, as we found only 16 cases of dementia with parkinsonism in women. Among them, eight cases were found in farmers, leading to a large confidence interval. Lack of power could explain why we did not find any association among men. Thus, these results need to be confirmed in larger sample.
In conclusion, risk of Alzheimer's disease does not seem to be influenced by occupation, and the relation between occupation and dementia seems to be limited to dementia with parkinsonism. The increased risk for this disease among farmers could be due partially to differences in health behaviour and perhaps because of exposure to environmental factors. The reason why these results were found particularly among women should be explored further. A larger sample of subjects with dementia with parkinsonism with more precise measurements of the type and duration of exposures to environmental factors-for instance, by means of a job exposure matrix - are needed to confirm these findings.

This study was supported by grants from Fondation de France, Novartis Pharma, Axa Insurance Group, Caisse Nationale d'Assurance Maladie, Caisse Primaire d'Assurance Maladie de Dordogne, Conseil Général de la Dordogne, Conseil Général de la Gironde, Conseil Régional d'Aquitaine, Danone, Ministère de la Recherche et de la Technologie, Mutualité Sociale Agricole de Gironde et Dordogne, Mutuelle Générale de l'Education Nationale, Société Pechiney, 2010 Media, and veau, Direction Régionale des Affaires Sanitaires et Sociales d'Aquitaine.

1 Zhang MY, Katzman R, Salmon D, et al. The prevalence of dementia and Alzheimer's disease in Shangai, China: impact of age, gender, and education. Ann Neurol 1990;27:428-37.

2 Fratiglioni L, Grut M, Forsell Y, et al. Prevalence of Alzheimer's disease and other dementias in an elderly urban population: relationship with age, sex, and educaion. Neurology 1991;41:1886-92.

3 Letenneur L, Gilleron V, Commenges D, et al. Are sex and educational level independent predictors of dementia and Alzheimer's disease? Incidence data from the PAQUID project. F Neurol Neurosurg Psychiatry 1999;66:177-83.

4 Beard CM, Kokmen E, Offord KP, et al. Lack of association between Alzheimer's disease and education, occupation, marital status, or living arrangement. Neurology 1992;42: 2063-8

5 Bickel H, Cooper B. Incidence and relative risk of dementia in an urban elderly population: findings of a prospective field study. Psychol Med 1994;24:179-92.

6 Stern Y, Gurland B, Tatemichi TK, et al. Influence of education and occupation on the incidence of Alzheimer's disease. FAMA 1994;271:1004-10.

7 Bonaiuto S, Rocca WA, Lippi A, et al. Education and occupation as risk factors for dementia: a population-based
panto pation as risk factors for dementia: a population-base

8 Mortel KF, Meyer JS, Herod B, et al. Education and occupation as risk factors for dementias of the Alzheimer and schemic vascular types. Dementia 1995;6:55-62.

9 Paykel ES, Brayne C, Huppert FA, et al. Incidence of dementia in a population older than 75 years in the United Kingdom. Arch Gen Psychiatry 1994;51:325-32.

10 Callahan CM, Hall KS, Hui SL, et al. Relationship of age, education, and occupation with dementia among a rol 1996;53:134-40.

11 Evans DA, Hebert LE, Beckett LA, et al. Education and other measures of socioeconomic status and risk of incident Alzheimer disease in a defined population of older persons. Arch Neurol 1997;54:1399-405.

12 Jorm AF, Rodgers B, Henderson AS, et al. Occupation type as a predictor of cognitive decline and dementia in old age. As a predictor of cognitive decing 1998;27:477-83.

13 Kokmen E, Ozsarfati Y, Beard CM, et al. Impact of referral Kokmen E, Ozsarfati Y, Beard CM, et al. Impact of referral
bias on clinical and epidemiological studies of Alzheimer's bias on clinical and epidemiological studies
disease. $\mathcal{F}$ Clin Epidemiol 1996;49:79-83.

14 Dartigues JF, Gagnon M, Letenneur L, et al. Principal lifetime occupation and cognitive impairment in a French elderly cohort. Am f Epidemiol 1992;135:981-8.

15 Dartigues JF, Gagnon M, Mazaux JF, et al. Occupation during life and memory performances in non-demented French elderly community residents. Neurology 1992;42: 1697-701.

16 Folstein MF, Folstein SE, McHugh PR. "Mini mental state". A practical method for grading the cognitive state of
patients for the clinician. $\mathcal{F}$ Psychiatr Res $1975 ; 12: 189-98$.

17 Institut National des Statistiques et Etudes Economiques. Nomenclature des professions et catégories socioprofessionnelles. Paris INSEE, 1982.

18 American Psychiatric Association. Diagnostic and statistical manual of mental disorders, 3rd edition revised (DSM III-R). manual of mental disorders, 3rd

19 McKhann G, Drachman D, Folstein M, et al. Clinical diagnosis of Alzheimer's disease: report of the NINCDSADRDA work group under the auspices of Department of 
Health and Human Services Task Force on Alzheimer's disease. Neurology 1984;34:939-44.

Cerebral blood flow in dementia. Arch Neurol 1975;32:632-7.

21 Launer LJ, Andersen K, Dewey ME, et al. Rates and risk factors for dementia and Alzheimer's disease. Results from EURODEM poote

22 Roman G, Tatemichi T, Erkinjuntti $T$, et al. Vascula dementia: diagnostic criteria for research studies. Report of the NINDS-AIREN International Workshop. Neurology 1993;43:250-60.

23 The Lund and Manchester Groups. Clinical and neuropathological criteria for frontotemporal dementia. $7 \mathrm{Neu}-$ rol Neurosurg Psychiatry 1994;57:416-18.

24 McKeith I, Galasko D, Kosaka K, et al. Consensus guidelines for the clinical and pathologic diagnosis of guidelines with (the 1996;47:1113-24.

25 Litvan I, Agid Y, Calne D, et al. Clinical research criteria for the diagnosis of progressive supranuclear palsy (SteeleRichardson-Olszewski syndrome): report of the NINDSSPSP international workshop. Neurology 1996;47:1-9.
26 The Consensus Committee of the American Autonomic Society and the American Academy of Neurology. Consensus statement on the definition of orthostatic hypotension, pure autonomic failure, and multiple system atrophy. Neurology 1996;46:1470.

27 Breslow N, Day N. Statistical method in cancer research. Vol2. The design and analysis of cohort studies. Lyon: IARC Sci Publ (82), 1987.

28 Commenges D, Letenneur L, Joly $\mathrm{P}$, et al. Modelling age specific risk: application to dementia. Stat Med 1998;17: 1973-88.

29 Blacker D, Albert M, Bassett S, et al. Reliability and validity of NINCDS-ADRDA criteria for Alzheimer's disease. The National Institute of Mental Health Genetics Initiative. Arch Neurol 1994;51:1198-204.

30 Snowdon DA, Kemper SJ, Mortimer JA, et al. Linguistic ability in early life and cognitive function and Alzheimer's disease in late life. Findings from the Nun study. $\mathcal{F} A M A$ 1996;275:528-32.

31 Menegon A, Board PG, Blackburn AC, et al. Parkinson's disease, pesticides, and glutathione transferase polymorphisms. Lancet 1998;352:1344-6.

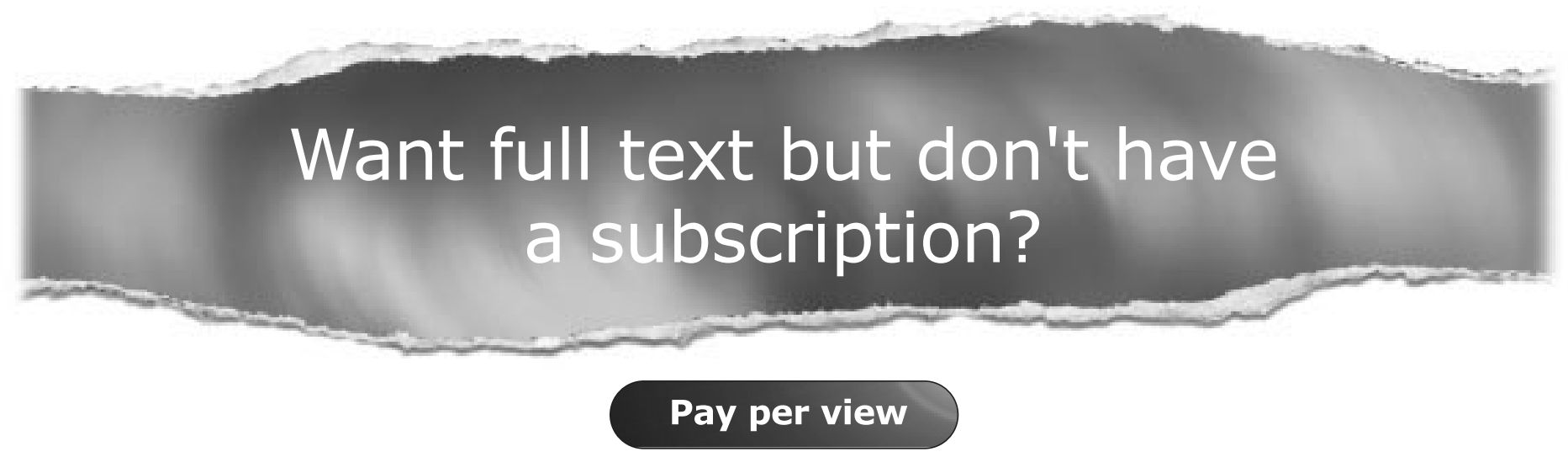

For just $\$ 8$ you can purchase the full text of individual articles using our secure online ordering service. You will have access to the full text of the relevant article for 48 hours during which time you may download and print the pdf file for personal use.

www.jnnp.com 